\title{
A Proposta da Redução da Maioridade Penal na Perspectiva das Equipes Técnicas das Medidas Socioeducativas de Internação
}

\section{The Proposal of the Reduction of Criminal Responsibility Age under the Perspective of Technical Teams of Socio-Educational Measures of Internment}

\author{
Fábio de Carvalho Mastroianni (orcid.org/0000-0002-0539-8252) \\ Márcio Istruder2 (orcid.org/0000-0003-2793-0403) \\ Thaís Pamela Portolani³ (orcid.org/0000-0002-3869-8294)
}

\begin{abstract}
Resumo
A proposta de redução da maioridade penal tem gerado algumas controvérsias. Objetivou-se explorar como os profissionais das equipes técnicas de internação de instituições localizadas no interior do estado de São Paulo compreendem a referida proposta, bem como a efetividade das estratégias já previstas no estatuto. Realizou-se um estudo descritivo, exploratório e analítico de referencial qualitativo. Utilizando-se um roteiro de entrevista, os dados foram analisados pela técnica de análise de conteúdo. A amostra foi composta por oito participantes mulheres com formação em Psicologia ou Serviço Social, que trabalham no atendimento a adolescentes em cumprimento de medida socioeducativa de internação. Todas se posicionaram contra a proposta, pois a consideram uma medida simplista a um problema complexo, traduzida em resposta a um apelo por justiça por parte da sociedade, influenciada por questões midiáticas e políticas que não correspondem aos dados da realidade. Avaliam-na como uma proposta excludente e ponderam que mudanças efetivas devam se pautar na lógica restaurativa, baseada nos preceitos do estatuto e no investimento em políticas públicas.
\end{abstract}

Palavras-chave: Adolescente autor de ato infracional. Maioridade penal. Medida socioeducativa. Pesquisa qualitativa.

\footnotetext{
Abstract

The proposal of the reduction of criminal responsibility age has generated some controversies. This study aimed to explore how the technical staff from the socio-educational measures of interment, located in the interior of São Paulo State, understands the proposal, as well as the effectiveness of the strategies already provided by the statute. A

1 Universidade de Araraquara. Tribunal de Justiça do Estado de São Paulo, Araraquara; São Paulo, Brasil. E-mail: psicomastroianni@gmail.com.

2 Universidade de Araraquara, Araraquara, Brasil. E-mail: marcio_istruder@hotmail.com.

${ }^{3}$ Universidade de Araraquara, Araraquara, Brasil. E-mail: thaisportolani_tpp@hotmail.com.
} 
descriptive, exploratory and analytical study of qualitative reference was carried out. Using an interview script, data were analyzed through the technique of content analysis. The sample consisted of eight female participants with background in Psychology or Social Service who work in the attendance of adolescents in compliance of socioeducational measures of interment. All of them were against the proposal, as they consider it to be an oversimplified measure to a complex problem, reflexing a response to an appeal for justice on the part of society, influenced by media and political issues that do not correspond to reality data. They evaluate it as an excluding proposal and consider that effective change should be guided by the restorative justice, based on the precepts of the statute and investment in public policies.

Keywords: Adolescent author of an infraction act. Criminal responsibility. Socio-educational measures. Qualitative research. 


\section{Introdução}

Alguns historiadores, entre eles Ariés (1981), realizaram estudos que ajudam a compreender como o conceito de infância e o sentimento dos adultos por esses indivíduos foram se transformando ao longo da história da humanidade. Embora seja consenso de que existe um período inicial na vida em que características e demandas específicas são comuns a todos os indivíduos, nem sempre a infância ou os indivíduos pertencentes a esse período tiveram a mesma atenção e consideração dos adultos (Rocha, 2002).

Tanto na História da humanidade quanto na História do Brasil se observam diversos relatos de experiências de maus-tratos, violência, exclusão e abuso sexual praticados contra crianças e adolescentes (Alberto, Almeida, Guedes, Sousa \& França, 2008). Além disso, mesmo nos dias atuais, não se pode ignorar que esses indivíduos prosseguem figurando como vítimas de violência, muitas delas em decorrência da desigualdade e das diferenças sociais e econômicas que atingem inúmeras pessoas deste país, quando deveriam ser alvo de proteção e cuidado (Monte, Sampaio, Rosa Filho \& Barbosa, 2011).

Com relação à legislação, somente em 1927, por meio do Decreto n. 17.943-A, foi instituído no Brasil o primeiro documento legal destinado à população com menos de 18 anos, denominado Código de Menores. Na primeira versão, entretanto, o Estado cumpria uma função meramente punitiva, não existindo diferenças em relação ao tratamento penal de crianças, adolescentes e adultos (Moreira \& Miranda, 2007; Pitta \& Fontoura, 2009). Na segunda versão, Lei n. 6.679/1979, enfatizou-se a dicotomia em relação àqueles considerados em situação irregular, dividindo-os entre infância abandonada, considerada sem valor e com pouca perspectiva de futuro, e infância perigosa, que demandava a necessidade de intervenção do Estado (Brito, Ayres \& Amendola, 2006; Ciarallo \& Almeida, 2009).

No ano de 1988, a partir da abertura política e o fim da ditadura militar, foi criado o I Fórum Nacional Permanente de Entidades não Governamentais de Defesa dos Direitos da Criança e do Adolescente - esse evento, inspirado em diversos movimentos nacionais e internacionais que tiveram por base a proteção dos direitos humanos e o desenvolvimento de políticas de atendimento a crianças e adolescentes, mobilizou várias organizações que, juntas, elaboraram o projeto que resultou na criação da Lei n. 8.069/1990, denominada Estatuto da Criança e do Adolescente - ECA (Alberto et al., 2008).

O Estatuto surgiu com o objetivo de promover e assegurar os direitos fundamentais dessa população, visando garantir as oportunidades e facilidades, além de promover o saudável desenvolvimento físico, moral, mental e social, colaborando com a liberdade e a dignidade da criança e do adolescente. O termo menor, pelo menos do ponto de vista jurídico, foi substituído, visando, assim, evitar a interpretação de sujeitos em condição inferior, passando a abranger a infância de modo geral e não apenas aqueles considerados em situação de 
risco ou irregulares (Ciarallo \& Almeida, 2009; França, 2004).

$\mathrm{Na}$ prática, entretanto, tais garantias de oportunidades permanecem muitas vezes apenas no discurso jurídico, não se concretizando em políticas e programas de atendimento a esse público. Ao mesmo tempo, verifica-se que, embora devesse ter sido abandonado, o próprio termo "menor" ainda se mantém nos discursos de parte da população, principalmente naqueles que associam a criminalidade e a violência a determinados grupos, entre eles os adolescentes oriundos de classes menos privilegiadas (Brito, Ayres \& Amendola, 2006; Cairus \& Conceição, 2010; Ciarallo \& Almeida, 2009).

Nesse sentido, do ponto de vista jurídico, crianças e adolescentes deixaram de ser vistos como feixe de carências, dada as condições precárias em que a infância e a adolescência eram tratadas, passando a ser compreendidos como feixe de possibilidades abertas ao futuro, devendo-se investir em suas potencialidades, em vez de estigmatizar e justificar as ações repressivas devido as suas dificuldades (Ciarallo \& Almeida, 2009). O Estatuto, em seu art. 101, prevê a aplicação de medidas protetivas para aqueles que tiverem os seus direitos ameaçados por ação ou omissão do Estado, da sociedade, pais, responsáveis ou em razão de sua própria conduta (Volpi, 2010).

Aos adolescentes que se envolvem com práticas infracionais, o Estatuto prevê, em seu art. 112, a aplicação de medidas socioeducativas, sendo elas: advertência; obrigação de reparar o dano; prestação de serviço à comunidade; liberdade assistida; inserção ao regime semiaberto e internação socioeducativa. No entanto, conforme explicita o primeiro parágrafo do referido artigo, deve-se levar em conta a capacidade do adolescente em cumpri-la, as circunstâncias e a gravidade da situação (Francischini \& Campos, 2005; Monte et al., 2011; Volpi, 2010).

Tais medidas comportam aspectos de natureza coercitiva, uma vez que são punitivas, mas também incluem aspectos educativos, no sentido da proteção integral e promoção de acesso à formação e informação (Volpi, 2010). De acordo com o Estatuto, arts. 103, 104 e 105, considera-se ato infracional a conduta definida como crime ou contravenção penal, na qual os indivíduos com idade igual ou inferior a 18 anos são inimputáveis, correspondendo também a eles a aplicação das medidas protetivas previstas no art. 101. Apesar dos avanços, muitas críticas foram apontadas, entre elas, o Estatuto foi acusado de garantir apenas os direitos dos adolescentes, omitindo seus deveres e responsabilização quanto à prática dos atos infracionais (Ciarallo \& Almeida, 2009).

Sob a óptica jurídica, o termo mais utilizado atualmente é "adolescente em conflito com a lei", denominação que não visa rotular o indivíduo como infrator e delinquente, focalizando apenas o ato em si e não a essência do sujeito, considerado em condição de desenvolvimento (Ciarallo \& Almeida, 2009; Volpi, 2010). No entanto, Bernstein, Baptista, Girão e Verani (2011) sugerem uma nomenclatura inversa à que se tem utilizado, “a lei em conflito com o adolescente", para destacar as muitas vezes em que o Estado deixa de cumprir o seu dever de assegurar à criança e ao adolescente, com absoluta prioridade, muitos de seus direitos previstos tanto na Constituição quanto no Estatuto (Lei n. 8.069, 1990). 
Diante de um cenário de desigualdade social, associado à divulgação de adolescentes envolvidos em processos judiciais pelos meios de comunicação, pelo qual os seus atos se estendem também para crimes considerados hediondos, surge o debate e o fortalecimento da proposta da redução da maioridade penal, como resposta para punir adolescentes que cometem atos infracionais (Monte et al., 2011). De maneira geral, a referida proposta consiste em diminuir de 18 para 16 anos a inimputabilidade penal do adolescente.

Com relação ao tema, observam-se argumentos prós e contras e uma divisão da sociedade com relação à proposta. Aqueles que fundamentam a proposta, como o seu autor, o Senador Aloysio Nunes Ferreira, alegam que os adolescentes têm plena consciência de seus atos, tornando-se a lei omissa aos fatos ao isentá-los das consequências necessárias. Consideram haver correlação entre a violência, o avanço do mundo e o amadurecimento precoce dos adolescentes, tornando-se a proposta conveniente.

Além disso, destaca-se a PEC n. 171/1993 (Câmara dos Deputados), de autoria de Benedito Domingos (Deputado Federal pelo PP/DF), e a n. 115/2015 (Senado Federal). Observa-se que, em um primeiro momento, a discussão da redução da maioridade penal para 16 anos não especificava o tipo de ato infracional, ou seja, a redução era para todos, independentemente da gravidade do ato. Por se tratar de matéria complexa e que diz respeito às garantias e aos princípios fundamentais, são discutidas outras propostas, como a redução em casos de práticas de "crimes hediondos" e o aumento do tempo de cumprimento da medida socioeducativa de internação.

Contrária à proposta se observa a posição do Conselho Federal de Psicologia (CFP), o qual adverte que o foco real da violência cometida por adolescentes não deve ser perdido, devendo-se privilegiar o debate acerca da grande desigualdade social e, consequentemente, das condições precárias de vida às quais está submetida grande parte da população. O referido órgão considera essencial afirmar o adolescente como sujeito em desenvolvimento, por ser a infância e a adolescência uma fase com transformações fundamentais, privilegiando-se, portanto, a óptica educacional sobre esses indivíduos (CFP, 2013).

Diante dessa dicotomia entre a posição de certos setores da sociedade e de alguns autores com relação ao tema da violência praticada por adolescentes, mostra-se relevante explorar a compreensão dos profissionais que lidam diretamente com essa população, verificando-se como avaliam a efetividade das estratégias previstas no Estatuto e como observam a proposta da redução da maioridade penal como possível estratégia para o problema da violência.

\section{Objetivo}

A pesquisa teve por objetivo explorar como os profissionais da equipe técnica da medida socioeducativa de internação compreendem a proposta de redução da maioridade penal, bem como a efetividade das estratégias já previstas no Estatuto da Criança e do Adolescente. 


\section{Método}

Trata-se de um estudo descritivo, exploratório e analítico, baseado em um referencial qualitativo de pesquisa, que, segundo Ollaik e Ziller (2012), tem como finalidade a obtenção de dados descritivos por meio de um contato direto e interativo entre o pesquisador e o objeto de estudo. Nessa perspectiva, o pesquisador busca compreender os fenômenos a partir do ponto de vista dos participantes. Para Yin (2016), a pesquisa qualitativa tem o objetivo de expressar o sentido dos fenômenos no mundo social, reduzindo a distância entre a teoria e os dados; o contexto e a ação; caracterizada pela realização de um exame intensivo dos dados coletados.

\section{Participantes}

Foram selecionadas para o estudo somente profissionais com formação em Psicologia ou Serviço Social, profissões que compõem a equipe técnica das instituições responsáveis pela execução da medida socioeducativa de internação. A composição da amostra foi formada inicialmente por meio do contato com os profissionais que integram a equipe técnica de uma instituição localizada no interior do estado de São Paulo. A partir daí, utilizou-se a técnica da bola de neve, na qual os participantes iniciais indicaram outros profissionais, e assim sucessivamente, até se alcançar o ponto de saturação teórica (Biernacki \& Waldorf, 1981; Fontanella, Ricas \&, Turato, 2008; Strauss \& Corbin, 1998).

Segundo os autores, o ponto de saturação teórica é atingido quando os entrevistados passam a repetir conteúdos obtidos nas entrevistas anteriores, tornando-se redundantes, ou seja, nenhuma nova informação relevante é descoberta. Neste estudo, foi possível atingir o ponto de saturação teórica com oito entrevistas. Todos os participantes que compuseram a amostra residem e trabalham no mesmo município de escolha para o estudo, mas atuam em quatro distintas unidades de execução de medida de internação.

\section{Aspectos Éticos}

Por se tratar de um estudo envolvendo seres humanos, a pesquisa foi submetida ao Comitê de Ética em Pesquisa, aprovado sob o CAAE n. 43111915.6.0000.5383, com a finalidade de garantir a proteção e a integridade dos participantes da pesquisa e a segurança dos pesquisadores. A pesquisa também foi subsidiada pelo Comitê de Ética em Pesquisa da Fundação Casa e, depois de aprovada, foi realizado o contato com a unidade autorizada para se iniciar as entrevistas. Nesse sentido, antes de iniciar a coleta, foram realizados os devidos esclarecimentos, apresentando o Termo de Consentimento Livre e Esclarecido (TCLE), recomendado pela Resolução do Conselho Nacional de Saúde n. 466 (2013).

\section{Materiais e Instrumentos}

A entrevista baseou-se em um roteiro semiestruturado, contendo perguntas sobre a dinâmica de interação entre os profissionais e os adolescentes, suas principais funções $\mathrm{e}$ dificuldades na realização do trabalho. Além disso, explorou-se como os profissionais avaliam 
a efetividade das medidas socioeducativas e como compreendem a proposta de redução da maioridade penal. Para a coleta dos dados, depois do consentimento dos participantes, as entrevistas foram gravadas em áudio e em seguida analisadas.

\section{Local e Período de Coleta}

A pesquisa foi realizada em uma cidade localizada no interior do estado de São Paulo. As primeiras entrevistas foram realizadas com duas psicólogas e uma assistente social na própria unidade de internação e, posteriormente, na residência dos profissionais, que foram sendo indicados pelas primeiras participantes. Tais procedimentos ocorreram durante o primeiro semestre de 2015, em dias e horários previamente estabelecidos com os profissionais, respeitando-se a voluntariedade e a disponibilidade dos participantes.

\section{Procedimentos de Coleta e Análise de Dados}

As entrevistas foram realizadas individualmente, priorizando-se o sigilo e os cuidados para preservar a qualidade do áudio. Depois da apresentação dos objetivos e consentimento dos participantes, eles foram orientados a se apresentar para que, ao longo da entrevista, no momento adequado, as questões que compõem o roteiro pudessem ser introduzidas. As entrevistas tiveram entre $30 \mathrm{~min}$ e $1 \mathrm{~h}$ de duração, sendo possível realizá-las em apenas um encontro com cada participante.

Visando preservar a identidade dos participantes, preferiu-se identificá-los por meio de siglas que indicassem somente a formação, utilizando-se, portanto, "Ps" para aqueles com formação em Psicologia e "As" para os profissionais de Serviço Social, obtendo-se a seguinte sequência: "Ps1, Ps2, Ps3, Ps4, Ps5, Ps6, As1 e As2". Em seguida, utilizou-se a técnica de análise de conteúdo (Bardin, 1977), definida como uma técnica de tratamento de dados de pesquisa voltada para uma descrição objetiva e sistemática do conteúdo das mensagens.

Embora essa técnica tenha suas origens na pesquisa quantitativa, o objetivo é a interpretação de materiais de caráter qualitativo, classificando as mensagens em categorias que permitam entender o significado das comunicações (Caregnato \& Mutti, 2006; Gomes, 2012; Minayo, 1998). A partir dessa análise, os relatos foram separados por categorias de respostas, criando-se um arquivo com as respostas de todos os participantes em determinado conteúdo. Foram encontradas as seguintes categorias de respostas: visão sobre o adolescente que comete infração; dificuldades e satisfação com o trabalho; visão sobre as medidas socioeducativas; opinião sobre a proposta de maioridade penal e suas possíveis consequências, se aprovada.

\section{Resultados e Discussão}

\section{Características Gerais da Amostra}

Todas as oito participantes que compuseram a amostra são do sexo feminino, com idades entre 25 e 50 anos; a experiência profissional variou entre três e 18 anos e, de modo geral, ao serem contatadas, todas aceitaram participar do estudo, não ocorrendo 
nenhuma resistência ou recusa. No que se refere ao exercício de suas funções, todas indicaram satisfação em trabalhar na área. Cinco delas consideram que o mais atrativo consiste em desenvolver alguma habilidade e/ou mudança significativa nos adolescentes que elas acompanham.

[...] é muito raro você ganhar o pão de cada dia fazendo o que gosta, então eu me sinto privilegiada. (Ps1)

Gosto bastante da área de medidas socioeducativas. Acho que quem não gosta e não acredita, o trabalho é em vão. (As1)

Adoro [...] eu gosto muito de trabalhar com os meninos [...] a minha maior satisfação é trabalhar com eles, a gente percebe melhora. (Ps2)

Quando você consegue perceber que foi útil, que acolheu, que aplacou a angústia, que conseguiu minimamente direcionar aquele menino pra medida mais adequada, quando você percebe que minimamente o juiz tentou levar em consideração aquilo que você escreveu ou quando as famílias te ligam e agradecem, dizendo: "olha, era isso mesmo que ele estava precisando", então acho que isso é o que vale a pena. (Ps3)

Apesar da satisfação, não deixaram de apontar também as dificuldades com as quais se deparam no exercício profissional. Seis participantes relataram problemas relacionados, principalmente, ao modo como parte da sociedade, dos profissionais e membros da própria equipe de trabalho lidam com $\mathrm{O}$ adolescente que cometeu infração. Ponderam que o preconceito e a dificuldade, inclusive das instituições envolvidas no compromisso com a educação e a retomada da convivência familiar e comunitária dos adolescentes, muitas vezes pautada apenas na ideologia da vingança social, agravam ainda mais os problemas encontrados nesses adolescentes e suas famílias.

[...] eu acho que o pior entrave do nosso trabalho é essa coisa humana, que é o ímpeto de punir, de tentar extirpar o mal mesmo. (Ps1)

[...] o que mais frustra, o que mais decepciona, é este trabalho com a rede, este trabalho com o judiciário, que muitas vezes a gente percebe que não dá o crédito que a gente gostaria. (Ps2)

Dificuldade com as outras equipes, a gente tem muito problema com o setor de saúde, por exemplo, são pessoas ainda muito resistentes, com uma visão preconceituosa dos meninos [...] está ali e não suporta o objeto de trabalho, aí fica muito difícil você trabalhar com aquilo que você não suporta. (Ps3)

Os funcionários, a própria equipe, é o maior entrave, a gente tem pessoas que estão ali e não gostam do que fazem, pessoas que deveriam facilitar a permanência do menino, mas na verdade só pesam mais ainda, dificultam [...] é difícil lidar com a violência, a violência é muito grande, não só da instituição, eu acho que a gente vive uma cultura violenta, o nosso país é bastante violento e isso reflete na instituição [...] por exemplo, na maneira de se dirigir ao menino: o ladrão, o vagabundo. (Ps4)

A grande demanda de trabalho também foi citada por duas participantes, que consideram a sobrecarga um dos aspectos que dificultam a realização de suas funções, tornando, por vezes, as intervenções superficiais e menos efetivas.

[...] a questão das 30 horas semanais, que eu não sei se é uma evolução ou uma involução, porque o número de adolescente é o mesmo e o quadro de funcionários também, então se eu trabalhava 40 pra atender a quantidade que eu atendo hoje e eu trabalho 30, 
então de alguma forma tenho que me superar muito. (As2)

[...] número, quantidade de adolescentes que a gente precisa atender e isso limita muito a atuação, você não consegue dar um acompanhamento como você gostaria ou necessitaria [...] a gente atende muitos casos, e existem casos que você precisa dar uma atenção maior e você acaba não tendo tempo porque você tem que cumprir um protocolo pra todos, isso é difícil. (Ps6)

O discurso das entrevistadas indica que, além da sobrecarga de trabalho, elas enfrentam dificuldades até mesmo com outros profissionais, os quais, de modo geral, refletem alguns dos preconceitos já existentes na própria sociedade. De acordo com Francischini e Campos (2005), trabalhar com as medidas socioeducativas não é tarefa fácil, devido à existência de diversos obstáculos, tais como a concepção fechada e construída no seio da sociedade de irreversibilidade do quadro do indivíduo, a qual desacredita na possibilidade de convivência familiar e comunitária dos adolescentes em cumprimento de medida socioeducativa.

Essa concepção, segundo os autores, pode levar alguns profissionais a se mostrarem inflexíveis na crença a respeito da capacidade do adolescente em se recuperar e retornar ao convívio social. Destarte, os pesquisadores destacam a necessidade de cuidar de dois problemas: a saúde do adolescente privado de liberdade e a saúde mental do profissional que pode vir a desacreditar das suas próprias práticas e da recuperação desses adolescentes.

\section{Sobre o Adolescente e o Ato Infracional}

As profissionais, de maneira geral, não têm uma percepção do adolescente autor de ato infracional como um indivíduo com um perfil único, pois percebem as suas singularidades $\mathrm{e}$ associam tais práticas a movimentos próprios da adolescência: “[...] cada indivíduo é um indivíduo [...] eu acredito que eles vêm realmente pelas coisas próprias da adolescência” (As2). "[...] é muito individual, adolescente autor de ato infracional pra mim é adolescente" (Ps6).

No entanto, todas as entrevistadas destacam a condição de vulnerabilidade social que observam nesses adolescentes e suas respectivas famílias.

[...] a grande maioria é fruto do meio em que cresceu, da família em que cresceu, da falta de oportunidades. (Ps2)

[...] muitos deles vão ter pela primeira vez todos os seus direitos assegurados quando vem pra uma medida de internação. (As1)

[...] os adolescentes autores do ato infracional são os vulneráveis socialmente, são os negros, são os meninos de periferia, são os desassistidos [...] são meninos que não têm acesso, que não têm oportunidade, que querem ter como qualquer outro adolescente [...] a maior parte dos adolescentes que a gente recebe pouco lê, pouco escreve [...] isso interfere absurdamente na autoestima deles, na capacidade de analisar, de ver o mundo. (Ps4)

[...] muitas vezes tá na sexta série, mas é analfabeto, sem higiene bucal, praticamente nunca passou por um médico, ele não tem acesso a praticamente nenhuma política social básica. (As2)

A percepção das profissionais sobre as características dos adolescentes revela a escassez de investimento e a fragilidade das políticas 
públicas em garantir os seus direitos previstos no Estatuto. Ao mesmo tempo, os discursos correspondem aos achados da literatura, que invariavelmente apontam a prevalência de adolescentes cumprindo medidas socioeducativas oriundos de classes socioeconômicas mais carentes, com privação cultural e material, assim como baixas expectativas de futuro e de mobilidade social.

Costa e Assis (2006) e Gallo e Willians (2005), em estudos de revisão sobre o tema, destacam aspectos como a baixa escolaridade e as dificuldades de aprendizagem como fatores de risco para a conduta infracional de adolescentes. Nesse sentido, a fala das profissionais, associada aos dados da literatura, indica que a não garantia de direitos a esses adolescentes, como uma educação básica de qualidade, também os expõe a riscos, na medida em que se observa certa correlação entre privação educacional e prática de ato infracional.

\section{Sobre as Medidas Socioeducativas e a sua}

\section{Efetividade}

De modo geral, observa-se que as profissionais valorizam e consideram avançada a legislação vigente, porém, acreditam que nem sempre os princípios do Estatuto são respeitados, priorizando-se a cultura da punição. Seus discursos se assemelham e se complementam, verificando-se que nenhuma delas avalia a efetividade das medidas socioeducativas de forma isolada. Destacam a necessidade de haver maior integração entre as medidas e vinculam a sua funcionalidade com o investimento em políticas públicas, por meio da aplicação de medidas protetivas que, na visão das participantes, poderiam evitar as internações ou oferecer o respaldo necessário para que não ocorresse a reincidência.

A gente não respeita tanto o ECA, o
Estatuto é uma das leis mais brilhantes e
mais humanas que se tem $[. .$.$] a$
internação é medida breve e
excepcional, mas o judiciário brasileiro
aplica internação a torto e a direito, sem
que outras medidas menos restritivas
tivessem sido tentadas [...] é essa
fomentação do punir, achar que se a
gente trancar todo o mundo o problema
da violência tá resolvido, e na verdade o
que falta são politicas públicas, o que
falta é a gente investir na prevenção.
(Ps1) As medidas socioeducativas funcionariam melhor se outras medidas funcionassem também, as protetivas [...] a internação eu acho que deveria ser o último caso, pra mim é a UTI mesmo, quando tudo foi tentado e nada deu certo [...] acho que muitos juízes usam a internação de forma leviana, interna no primeiro processo sem tentar outras coisas. (Ps2)

Eu acredito nas medidas sim, mas acho que elas têm que ser melhor aplicadas, tem que ser melhor investidas. (Ps4)

Os discursos das entrevistadas correspondem ao que Cunha, Ropelato e Alves (2006) afirmam ao relacionar a cultura institucional como reflexo das ideias presentes no senso-comum, as quais parecem se pautar na lógica de que a violência irá diminuir se houver maior punição. Para Galvão e Camino (2011), a ênfase na punição pode ser vista como uma válvula de escape dos cidadãos diante do temor da insegurança proporcionada por um Estado que não consegue garantir os direitos básicos da sociedade. Para as autoras, o Estado deve investir em um sistema de segurança que almeje, acima de tudo, promover a ressocialização e a 
prevenção, investindo-se em educação e promoção dos direitos humanos e do desenvolvimento moral.

As entrevistadas avaliam que a internação pode ser necessária em determinados casos, mas algumas ponderam que nem sempre a avaliação da equipe técnica sobre determinados casos corresponde à visão que o poder judiciário tem sobre os atos infracionais e os adolescentes. A maioria acredita que a medida pode ser efetiva e em muitos casos é somente durante a internação que os adolescentes têm os seus direitos assegurados, mostrando-se descontentes com a não continuidade dessas intervenções depois do cumprimento da medida.

Eu acho que o judiciário não caminha junto, cada juiz atua de um jeito, tem juiz que é extremamente legalista, só olha $\mathrm{o}$ ato infracional em si e ignora totalmente a questão do desenvolvimento do adolescente. (Ps4)

O juiz interna muita gente que não tem que internar, que não teria necessidade [...] tem caso que a gente implora pro juiz liberar o menino e eles não liberam, internam. (Ps3)

Eu acho que ela consegue reorganizar a rotina, garante direitos que muitas vezes eles não tiveram até esse momento, só que eu acho que às vezes não é dada continuidade [...] penso que deveria haver acompanhamento, pra não precisar a mãe, quando sair daqui, procurar o Ministério Público por necessidade pequena. (As1)

Ele sai da internação e se quebra aquilo, ele não tem mais nenhum apoio, pois ele sai de lá e agora? Vou ter que ir atrás de uma escola, de um curso, de um trabalho e de repente não consegue. (Ps5)

Mais uma vez o discurso da maioria das profissionais indica o quanto os adolescentes que chegam à internação não tiveram seus direitos garantidos, sendo insuficientemente atendidos pelas escolas e pouco orientados à profissionalização. Durante a internação, são envidados esforços no sentido de garantir esse desenvolvimento, no entanto, quando afastados da estrutura oferecida pela internação, o adolescente não recebe o mesmo suporte da sociedade e demais políticas públicas.

Com relação à efetividade da medida em assegurar os direitos desses adolescentes, bem como a importância em se oferecer a continuidade dessas garantias (mesmo depois do término da medida), alguns estudos ressaltam a importância de se observar as especificidades sociais, principalmente no que tange às desigualdades sociais do país (Cairus \& Conceição, 2010). Para as autoras, a educação se constitui como o princípio fundamental que garante a convivência familiar e comunitária dos adolescentes e, portanto, deveria existir investimento mais amplo, não somente durante a execução das medidas, mas principalmente como forma de prevenir o envolvimento de adolescentes com práticas disfuncionais.

\section{Sobre a Proposta da Redução da Maioridade Penal}

Todas as entrevistadas demonstraram contrariedade em relação à proposta, pois, de maneira geral, consideram que outras questões devam ser levadas em consideração quando se discute o tema da violência. A forma como a mídia vem lidando com a questão foi criticada por cinco das entrevistadas; além disso, metade das participantes considera que a proposta tem objetivos políticos, que visam, por meio do discurso da redução da maioridade penal, 
oferecer à sociedade uma resposta para a insegurança que sentem por causa da violência.

Eu acho que é querer tratar o problema sem ver o problema na verdade da forma como ele acontece, reduzir a maioridade penal vai dar uma resposta à sociedade que tem essa formação de opinião pela mídia. (As1)

Eu acho que a mídia bombardeia e ela sensibiliza a sociedade, na realidade com dados que não são verdadeiros. (Ps2)

O que acontece é mais uma questão politica, de conseguir voto por conta do sentimento de insegurança da população. (Ps1)

Eu acho que tem um pouco de tudo sabe, tem um pouco de politica [...] a própria imprensa que eu acho que podia fazer um trabalho muito mais produtivo, construtivo, do que esse trabalho péssimo. (Ps3)

Metade das entrevistadas afirmou não existir dados estatísticos que comprovem a relação entre o aumento da violência com as infrações cometidas pelos adolescentes. Consideram que se trata de um problema muito mais complexo, e a aprovação da proposta, por si só, não resolveria o problema. Destacam a necessidade de se discutir sobre outros aspectos, bem como se investir em outras estratégias.

Acho que a violência não aumenta por causa do adolescente, a violência aumenta por causa de uma série de coisas e o adolescente é extremamente vulnerável. (Ps4)

Eu acho que tem que se preocupar com a questão de criar instrumentos pra melhorar a intervenção junto a esses meninos, essas famílias e a escola que tá um caos. (Ps3)

Não aumentou, os adolescentes continuam sendo muito mais assassinados do que assassinos, crime hediondo é muito maior no meio adulto do que na adolescência, reduzir a maioridade penal pra mim não soluciona, não resolve o problema porque não é esse o problema. (Ps2)

A gente precisa pensar também na questão da segurança pública, o combate ao crime organizado, é isso que tá acontecendo, eles vão tomando as periferias, eles vão tomando lugar e eles vão sendo referência. (As1)

Segundo Wolf (2003), a construção das mensagens veiculadas na mídia contribui com a formação de conceitos, atitudes e expectativas sociais, fatores esses que modificam a forma como a população lida com a questão. Ao priorizar determinados temas sociais, os meios de comunicação influenciam o consenso público, que, por sua vez, exige políticas públicas para o setor, gerando uma complexa interação entre imprensa, sociedade e governo, sendo que um alimenta o outro, tendo a imprensa como o intermediário entre a opinião pública e o governo.

Para Alves, Pedroza, Pinho, Presottti e Silva (2009), as distorções e exageros da mídia se tornam mais evidentes nos momentos de escolha dos representantes políticos, pois os candidatos geralmente propõem soluções rápidas e supostamente eficazes para o problema da violência. Destarte, ouvir e entender como os profissionais compreendem o tema se mostra fundamental, pois não é incomum observar os debates em torno de uma questão tão complexa como a violência serem direcionados e limitados apenas à institucionalização das ações.

A percepção das profissionais sobre a incongruência das estatísticas pode ser corroborada com os dados oriundos da Secretaria Geral da Presidência da República 
sobre a mortalidade por arma de fogo, os quais demonstram que o número de homicídios contra a população com idade entre 15 e 29 anos é praticamente o dobro, se comparada com a população total (Brasil, 2015). No ano de 2012, por exemplo, a taxa de mortalidade da população jovem foi de 47,6 (por cem mil habitantes), enquanto a da população geral foi de 21,9; diferença que, segundo o levantamento, vem se mantendo desde o ano de 2002.

Além disso, o Levantamento anual do Sistema Nacional de Atendimento Socioeducativo (Sinase), realizado no ano de 2014, indicou que os adolescentes restritos e privados de liberdade, ou seja, cumprindo medidas socioeducativas, representam apenas $0,1 \%$ dos adolescentes entre todos os indivíduos com idade entre 12 e 18 anos incompletos (Brasil, 2014). O discurso das entrevistadas, portanto, coaduna com Gonçalves e Garcia (2007), ao afirmarem que se devem buscar intervenções que ajam prioritariamente no sentido preventivo, com medidas que atendam melhor aos preceitos da proteção integral, como o investimento em políticas públicas e serviços de promoção e desenvolvimento social de qualidade.

As entrevistadas também ponderaram alguns riscos com a aprovação do projeto, entre eles, metade das participantes apontou a insuficiência do sistema prisional atual em dar conta dessa demanda, indicando que a medida poderia segregar ainda mais a população socialmente vulnerável. Além disso, sete das oito entrevistadas, ou seja, a grande maioria, assinalaram o risco de se diminuir cada vez mais a idade de envolvimento desses sujeitos com a criminalidade.
[...] reduzir essa maioridade só vai fazer o sistema (prisional) ficar mais inchado e mais inoperante, porque ele já não funciona. (Ps3)

[...] é segregar a pobreza, é colocar dentro de um muro, é uma forma de segregar a pobreza, a vulnerabilidade social. (Ps6)

[...] vai antecipar o envolvimento das crianças no envolvimento infracional, pois os que são maiores de idade vão buscar sempre aliciar aqueles que vão ter menos comprometimento. (Ps2)

Nós cada vez mais estamos recebendo crianças de 12 anos [...] vai ser aliciado cada vez com menos idade, nós vamos ter cada vez mais crianças de 12 anos na fundação casa, e é lógico que eu acho que basta aprovar os 16 anos pra ir pra cadeia, que vai baixar pra 10 anos pra ir pra fundação casa, isso interessa a quem? (As2)

Apenas duas das participantes consideraram a possibilidade de se aplicar medidas diferentes, distinguindo os adolescentes que tivessem cometido crimes mais graves ou hediondos. De qualquer forma, as entrevistadas consideraram tratar de uma população reduzida e que, em vez do encaminhamento ao sistema prisional, se pensasse em estratégias, como aumentar o tempo de internação.

[...] eu acho que para crimes hediondos tem que ter mudança sim [...] acho que crime hediondo teria que ter uma mudança, internação talvez um pouco maior de tempo. (Ps5)

[...] eu acredito que poderia até pensar numa internação mais longa, uma possibilidade de internação mais longa para crimes hediondos, que é um percentual muito pequeno, o inchaço da medida de internação são de casos muito mais leves e de casos que o meio aberto não conseguiu dar conta [...] a gente poderia ver e observar os casos de crimes hediondos especificamente e não 
pra tudo, e a redução tá abrangendo todo o mundo no mesmo pacote. (Ps6)

Alves et al. (2009) comentam a respeito da situação do sistema penitenciário brasileiro, o qual, segundo os autores, constitui-se em verdadeiro depósito humano, sem a garantia de higiene e integridade física dos indivíduos que ali se alocam. Para eles, a redução da maioridade penal pode agravar fortemente a situação de superlotação, o que reforça a visão de justiça retributiva. Além disso, consideram que encaminhar adolescentes que cometeram um número mínimo de infrações aos presídios seria como enviá-los às verdadeiras "escolas do crime", favorecendo o contato com indivíduos com longa experiência nessas práticas.

Interessante observar que, em um estudo realizado com parlamentares brasileiros (Corte Real \& Conceição, 2009), a representação social deles sobre o tema diverge das profissionais, aproximando-se mais do discurso do antigo Código de Menores, enquanto as participantes destacam as qualidades e os avanços do Estatuto. Destarte, é possível inferir que a maneira de os parlamentares lidar com o tema não considera o que pelo menos parte daqueles que atuam diretamente com esses adolescentes pondera sobre essa questão.

Diferentemente do que parte da população poderia pensar a respeito do trabalho dessas equipes, verifica-se que para essas profissionais o adolescente que se envolveu com ato infracional não é representado como alguém que deve ser segregado da sociedade. Pelo contrário, as entrevistadas percebem evolução e estão satisfeitas com o trabalho que desenvolvem, sem deixar de mensurar os limites de suas intervenções, pois compreendem que a vulnerabilidade social em que muitas famílias se encontram e sua inexorável relação com a violência não são questões que podem ser resolvidas apenas por uma ou outra instituição, mas sim pela sociedade como um todo, amparada pelo Poder Público.

Durante a pesquisa, muitas discussões sobre a proposta da redução da maioridade penal estiveram em pauta no Poder Legislativo, o que levou os meios de comunicação a divulgar os debates e sensibilizar a população a refletir sobre o tema. Apesar das limitações, entrevistas com poucos profissionais e restritos a um único município, o estudo procurou abrir espaço para que essas equipes também pudessem ser incluídas e ouvidas no debate.

\section{Considerações Finais}

O estudo permitiu explorar como os profissionais da equipe técnica da medida socioeducativa de internação compreendem a proposta de redução da maioridade penal, bem como a efetividade das estratégias já previstas no Estatuto. Embora a amostra tenha sido composta por profissionais de duas áreas distintas e de diferentes unidades, não se observou divergências em seus discursos. Além disso, todas se mostraram receptivas em discutir sobre o tema, sentindo-se à vontade para avaliar a estratégia segundo a realidade que observam na prática.

As profissionais percebem evolução e efetividade no trabalho com os adolescentes, sendo essa a maior fonte de satisfação do trabalho que desenvolvem. No entanto, se deparam com algumas dificuldades, pois 
observam que nem sempre a sociedade, os outros profissionais e as outras instituições envolvidos com a proteção da infância e da juventude compreendem a importância do trabalho que é desenvolvido na internação. Consideram que uma parcela desses setores se pauta em uma lógica retributiva, baseada em um sentimento de vingança social, em vez da lógica restaurativa, na qual as medidas socioeducativas são entendidas como estratégias que visam promover o crescimento e a retomada dos adolescentes à convivência familiar e comunitária.

Nesse sentido, destacam a importância em se desconstruir essa visão punitiva, fomentando maior integração entre os profissionais e instituições que compõem a rede de proteção. Em vez da punição, enfatizam a necessidade de investimento em prevenção e promoção, principalmente antes e depois do período da internação, pois percebem existir pouco espaço para esses adolescentes ou incentivos suficientes de ações que impeçam a sua internação ou garantam o prosseguimento de intervenções e direitos, muitas vezes, só oferecidos durante a medida, por exemplo: uma educação de qualidade.

Sendo assim, um ponto relevante trazido pelas profissionais e apontado pela literatura se refere à vulnerabilidade social desses sujeitos e suas famílias. De modo geral, se observa um contexto de precariedade e falta de recursos, ratificando-se, portanto, a necessidade de se investir em políticas públicas que garantam o desenvolvimento adequado, em vez de classificá-los ou responsabilizá-los pelas dificuldades e problemas que pertencem à sociedade como um todo, e não restrito a um determinado grupo de pessoas num período da vida.

Com relação à proposta da redução da maioridade penal, todas se mostraram contrárias, pois consideram que a estratégia se apresenta como uma solução simplista para enfrentar um problema muito mais complexo, podendo expor os adolescentes cada vez mais cedo à violência, bem como segregar cada vez mais as classes mais vulneráveis. Além disso, apontam a possibilidade de interesses políticos por trás dessas estratégias, bem como criticam o modo pelo qual os meios de comunicação têm discutido a questão, uma vez que no cotidiano de suas práticas não observam que o aumento da violência esteja atrelado à adolescência, especificamente.

Pelo contrário, apontam diversos outros fatores que ultrapassam a intervenção das equipes técnicas ou a simples punição como instrumentos para lidar com essas questões, incluindo a participação da sociedade e do Poder Público como autores dessa mudança. Durante a realização da pesquisa, a proposta de redução da maioridade penal permaneceu sendo debatida e prosseguiu gerando controvérsias, o estudo permitiu ouvir os profissionais que acompanham os sujeitos-alvo da proposta, mas não pretende encerrar a discussão.

Levar em consideração a visão dessas equipes se mostra importante para subsidiar as discussões sobre o tema e, apesar das limitações, os apontamentos realizados podem ampliar a compreensão sobre questões relativas à violência e à efetividade das medidas, devendo-se enfatizar a importância de outras pesquisas que possam enfocar diferentes contextos (outros estados e regiões) e populações (operadores do Direito e população em geral). 


\section{Referências}

Alberto, M. F. P., Almeida, D. R., Guedes, P. C., Sousa, T. R., \& França. W. L. P. (2008). O papel do psicólogo e das entidades junto a crianças e adolescentes em situação de risco. Psicologia, Ciência e Profissão, 28(3), 558-573. Recuperado em 6 abril, 2016, de http://pepsic.bvsalud.org/pdf/pcp/v28n 3/v28n3a10.pdf.

Alves, C., Pedroza, R.; Pinho, A., Presotti, L., \& Silva, F. (2009). Adolescência e maioridade penal: reflexões a partir da Psicologia e do Direito. Psicologia Política, 9(17), 67-83. Recuperado em 6 abril, 2016, de

http://pepsic.bvsalud.org/pdf/rpp/v9n1 7/v9n17a05.pdf.

Ariés, P. (1981). História social da criança e da família (2a ed.). São Paulo: LTC editora.

Bardin, L. (1977). Análise de conteúdo. Lisboa: Edições 70.

Bernstein, A. B., Baptista, C. P., Girão, R. S., \& Verani, S. S. (2011). Adolescentes, drogas, lei e Poder Judiciário: conflitos e desafios. In E. A. Silva \& D. de Micheli, D. (Orgs.). Adolescência, uso e abuso de drogas: uma visão integrativa (pp. 377-398). São Paulo:

Editora Fap-Unifesp.

Biernacki, P., \& Waldorf, D. (1981). Snowball Sampling: Problems and Techniques of Chain Referral Sampling. Sociological Methods and Research, 10(2), 141-163.

Retrieved from April 6, 2016, http://smr.sagepub.com/content/10/2/1 41.short.

Brasil. (2015). Mapa da Violência 2015: Mortes Matadas por Armas de Fogo. Brasília: Secretaria Geral da Presidência da República. Recuperado em 6 abril, 2016, de http://www.mapadaviolencia.org.br/pdf2015/ mapaViolencia2015.pdf.

Brasil. (2014). Levantamento Anual Sinase 2014. Brasília: Secretaria de Direitos Humanos. Recuperado em 20 julho, 2017, de http://www.sdh.gov.br/noticias/pdf/levantame nto-sinase-2014.
Brito, L., Ayres, L., \& Amendola, M. (2006). A escuta de crianças no sistema de Justiça. Psicologia e Sociedade, 18(3), 68-73. Recuperado em 6 abril, 2016, de http://www.scielo.br/pdf/psoc/v18n3/a 10v18n3.pdf.

Cairus, R., \& Conceição, M. I. G. (2010). Adolescentes na corda bamba: aspectos psicossociais na relação com a lei. Revista de Psicologia Política, 10(20), 275-292. Recuperado em 6, abril, 2016, de http://pepsic.bvsalud.org/pdf/rpp/v10n 20/v10n20a07.pdf.

Caregnato, R. C. A,. \& Mutti R. (2006). Pesquisa qualitativa: análise de discurso versus análise de conteúdo. Texto Contexto Enfermagem, 15(4), 679-684. Recuperado em 6 abril, 2016, de http://www.scielo.br/pdf/tce/v15n4/v1 $5 \mathrm{n} 4 \mathrm{a} 17$.

Ciarallo, C. R. C. A., \& Almeida, A. M. O. (2009). Conflito entre práticas e leis: a adolescência no processo judicial. Fractal, 21(3), 613-630. Recuperado em 6 abril, 2016, de http://www.scielo.br/pdf/fractal/v21n3/ 14.pdf.

Conselho Federal de Psicologia. (2013). Redução da idade penal: socioeducação não se faz com prisão. Brasília: CFP.

Corte Real, F. G. V., \& Conceição, M. I. G.. (2013). Representações sociais de parlamentares brasileiros sobre a redução da maioridade penal. Psicologia: Ciência e Profissão, 33(3), 656-671. Recuperado em 6 abril, 2016, de http://www.scielo.br/pdf/pcp/v33n3/v3 3n3a11.pdf.

Costa, C. R. B. S. F., \& Assis, S. G. (2006). Fatores protetivos a adolescentes em conflito com a lei no contexto socioeducativo. Psicologia e Sociedade, 18(3), 74-81. Recuperado em 6 abril, 2016, de http://www.scielo.br/pdf/psoc/v18n3/a 11v18n3.pdf.

Cunha, P. I., Ropelato, R., \& Alves, M. P. (2006). A redução da maioridade penal: questões teóricas e empíricas. Psicologia Ciência e Profissão, 26(4), 646-659. Recuperado em 6 
abril, 2016, de

http://www.scielo.br/pdf/pcp/v26n4/v2 6n4a11.

Decreto n. 17.943-A, de 12 de outubro de 1927. (1927). Consolida as leis de assistência e proteção a menores. Recuperado em 6 abril, 2016, de https://www2.camara.leg.br/legin/fed/d ecret/1920-1929/decreto-17943-a-12outubro-1927-501820-publicacaooriginal1-pe.html.

Fávero, E. T., Melão, M. J. R., \& Jorge, M. R. T. (2005). O Serviço Social e a Psicologia no judiciário: construindo saberes, conquistando direitos. São Paulo: Cortez.

Fontanella, B. J. B., Ricas, J., \& Turato, E. R. (2008). Amostragem por saturação em pesquisas qualitativas em saúde: contribuições teóricas. Cadernos de Saúde Pública, 24(1), 17-27. Recuperado em 6 abril, 2016, de http://www.scielo.br/pdf/csp/v24n1/02 .pdf.

França, F. (2004). Reflexões sobre a Psicologia Jurídica e seu panorama no Brasil. Psicologia: Teoria e Prática, 6(1), 73-80. Recuperado em 6 abril, 2016, de http://pepsic.bvsalud.org/pdf/ptp/v6n1 /v6n1a06.pdf.

Francischini, R., \& Campos, H. R. (2005). Adolescentes em conflito com a lei e medidas socioeducativas: limites e (im)possibilidades. Psico, 36(3), 267-273. Recuperado em 6 abril, 2016, de http://revistaseletronicas.pucrs.br/ojs/in dex.php/revistapsico/article/viewFile/13 $97 / 1097$.

Gallo, A. E., \& Williams, L. C. A. (2005). Adolescentes em conflito com a lei: uma revisão dos fatores de risco para conduta infracional. Psicologia: Teoria e Prática, 7(1), 81-95. Recuperado em 6 abril, 2016, de http:/ / www.redalyc.org/articulo.oa?id=1 93817415007.

Galvão, L. K. S., \& Camino, C. P. S. (2011). Julgamento moral sobre a pena de morte e redução da maioridade penal. Psicologia e Sociedade, 23(2), 228-236. Recuperado em 6 abril, 2016, de http://www.scielo.br/pdf/psoc/v23n2/a 03v23n2.pdf.

Gomes, R. (2012). Análise e interpretação de dados de pesquisa qualitativa. In M. C. S. Minayo (Org.). Pesquisa social: teoria, método e criatividade (pp. 79-108). Rio de Janeiro: Vozes.

Gonçalves, H. S., \& Garcia, J. (2007). Juventude e sistema de direitos no Brasil. Psicologia, Ciência e Profissão, 27(3), 538-553.

Recuperado em 6 abril, 2016, de http:/ /dx.doi.org/10.1590/S141498932007000300013.

Lei n. 8.069, de 13 de julho de 1990. (1990). Dispõe sobre o Estatuto da Criança e do Adolescente e dá outras providências. Recuperado em 6 abril, 2016, de http://www.planalto.gov.br/ccivil_03/lei s/18069.htm.

Lei n. 6.697, de 10 de outubro de 1979. (1979). Institui o Código de Menores. Recuperado em 6 abril, 2016, de https:/ / www2.camara.leg.br/legin/fed/le i/1970-1979/lei-6697-10-outubro-1979365840-publicacaooriginal-1-pl.html.

Menezes, C. D. (2009). Famílias de crianças e adolescentes no âmbito da justiça: a intersetorialidade como caminho. In B. M. Paulo (Coord.). Psicologia na Prática Jurídica: a criança em foco (pp. 61-78). Rio de Janeiro: Impetus.

Minayo, M. C. S. (1998). O desafio do conhecimento: pesquisa qualitativa em saúde. São Paulo: Hucitec, Abrasco.

Monte, F. F. C., Sampaio, L. R., Rosa-Filho, J. S., \& Barbosa, L. S. (2011). Adolescentes autores de atos infracionais: Psicologia Moral e legislação. Psicologia \& Sociedade, 23(1), 125-134. Recuperado em 6 abril, 2016, de http://www.scielo.br/pdf/psoc/v23n1/a 14v23n1.pdf.

Moreira, J. S. S., \& Miranda, V. R. (2007). Reinserção familiar: sim ou não?: diferentes facetas de uma longa e difícil história familiar. In M. C. N. Carvalho \& V. R. Miranda (Orgs.). Psicologia Jurídica: 
Temas de Aplicação I (pp. 61-78). Curitiba: Juruá.

Ollaik, L. G., \& Ziller, H. M. (2012).

Concepções de validade em pesquisas qualitativas. Educação e Pesquisa, 38(1), 229241. Recuperado em 6 abril, 2016, de http://www.scielo.br/pdf/ep/v38n1/ep4 48.pdf.

Pitta, D. S., \& Fontoura, T. (2009). O direito da criança e do adolescente à convivência familiar: uma questão de políticas públicas?. In M. C. N. Carvalho, T. Fontoura \& V. R. Miranda (Orgs.). Psicologia Jurídica: Temas de Aplicação II (pp. 143-164). Curitiba: Juruá.

Resolução n. 466, de 12 de dezembro de 2012. (2013). Aprova as diretrizes e normas regulamentadoras de pesquisas envolvendo seres humanos. Recuperado em 6 abril, 2016, de http://conselho.saude.gov.br/resolucoes /2012/Reso466.pdf.

Rocha, R. C. L. (2002). História da infância: reflexões acerca de algumas concepções correntes. Analecta, 3(2), 51-63.

Recuperado em 6 abril, 2016, de https://pt.scribd.com/doc/28155072/his toria-da-infancia-reflexoes-acerca-dealgumas-concepcoes-correntes.

Strauss, A., \& Corbin, J. (1998). Basics of Qualitative Research: Techniques and Procedures for Developing Grounded Theory (2nd ed.). London: Sage Publications Editor.

Volpi, M. (2010). O adolescente e o ato infracional (8a ed.). São Paulo: Cortez.

Wolf, M. (2003). Teoria das Comunicações de Massa. São Paulo: Martins Fontes.

Yin, R. K. (2016). Pesquisa Qualitativa do início ao fim. Porto Alegre: Penso.

Recebido em: 19/1/2018

Aprovado em: 19/7/2018 